Kopish, M. \& Marques, W. Leveraging Technology to Promote Global Citizenship in Teacher Education in the United States and Brazil

\title{
Leveraging Technology to Promote Global Citizenship in Teacher Education in the United States and Brazil
}

\author{
Michael Kopish, PhD.* \\ Ohio State University \\ Welisson Marques, PhD \\ Instituto Federal do Triângulo Mineiro in Uberaba \\ *Corresponding Author: kopish@ohio.edu \\ Received : 2019-09-01 \\ Accepted : 2019-10-21
}

How to cite this paper: Kopish, M. \& Marques, W. (2020) Leveraging technology to promote global citizenship in teacher education in the United States and Brazil. Research in Social Sciences and Technology, 5(1), 45-69.

\begin{abstract}
With globalization and the increase of technology, collaborative work between institutions from different countries is a reality. Beginning in 2018, two teacher education programs, one in the United States and one in Brazil, developed a partnership to promote collaborative activities in curriculum and instruction, scholarship and research, and for student and faculty exchange. Critical pedagogy and social justice approaches to global citizenship education in teacher preparation guided the partnership's collaborative activities toward the development of pre-service teachers' global competencies and ability to integrate technologies as users and educators. This empirical research article presents an exploratory case study of a transnational, collaborative curricular project that leveraged technology in courses for pre-service teachers in the United States $(n=12)$ and Brazil $(n=10)$. The study explores the extent to which course content and activities facilitated pre-service teachers' development of global competencies and ability to employ emerging technologies for learning and offers implications for practice.
\end{abstract}

Keywords: Collaborative online learning, Competences, Globalization, Pre-service teachers

\section{Introduction}

To address the demands of globalization, educational institutions are called upon to prepare students to face the challenges and opportunities of a global workforce. Researchers and stakeholders alike argue that at all levels of education, the future success of young people and graduates depends on: 1) being technologically competent in order to use a variety of technological tools (Hamel, 2007; ISTE 2017; Moore \& Simon, 2015; Partnership for 21st Century Skills, 2011; Stearns, 2009; West, 2010), and 2) being globally competent in order to work with diverse and geographically dispersed people and act on globally significant issues (Asia Society, 2011; Boix-Mansilla \& Jackson, 2011; Longview Foundation, 2008; OECD, 2018; 
Kopish, M. \& Marques, W. Leveraging Technology to Promote Global Citizenship in Teacher Education in the United States and Brazil

Osler \& Vincent, 2002; Standish, 2012, 2014; UNESCO, 2015; U.S. Department of Education, 2017; World Savvy, 2018). In a world that is increasingly interconnected, developing technological and global competencies with students at all levels is imperative for our global future.

Broadly, competencies in education are defined as a student's ability to transfer learning in and/or across content areas, often through an organizational framework that articulates learning outcomes in domains such as knowledge, skills, and dispositions or attitudes. For example, frameworks that outline technological competencies emphasize the capacity for innovation, leadership, multidisciplinary collaboration, collective problem identification, and resolution in dynamic digital environments (Hamel, 2007; ISTE 2017; Partnership for 21st Century Skills, 2008). Frameworks for global competencies (Asia Society, 2011; Boix-Mansilla \& Jackson, 2011; OECD, 2018; UNESCO, 2015; World Savvy, 2018) organize around cognitive (i.e., knowledge of global issues, trends, and globalization processes using analytical and critical thinking), socio-emotional (i.e., dispositions of empathy, valuing multiple perspectives, appreciation for diversity, and a sense of responsibility toward a common humanity), and behavioral domains (i.e., skills related to effective intercultural communication and collaboration, including speaking more than one language and acting on issues of global significance (Tichnor-Wagner et al., 2019, pp. 4-5). At the forefront in the design and enactment of curricula to develop technological and global competencies, teachers and teacher educators are essential.

With globalization and the increased use of technology, collaborative work between institutions from different countries is a reality (Lindsay \& Redmond, 2017). Beginning in 2018, two teacher education programs, one in the United States and one in Brazil, developed a partnership to promote collaborative activities in curriculum and instruction, scholarship and research, and for student and faculty exchange. During the spring/fall semester of 2019, the two authors employed a Collaborative Online International Learning (COIL) approach with teacher education courses at their respective institutions. Together, the authors co-designed a series of collaborative activities, seeking to develop teacher education students' global competencies (Boix-Mansilla \& Chua, 2016) and technological competencies (Uerz, Volman, \& $\mathrm{Kral}, 2018)$. This manuscript presents a reflective inquiry that explores the extent to which course content and activities facilitated pre-service teachers' development of global and technological competencies, and offers implications for practice.

\section{Literature Review}

\section{Teachers' Technological Competencies}

Current and future teachers alike are expected to keep up with the requirements and demands of technology in education. Teachers are expected to develop innovative ways to employ technologies as tools to enhance teaching and learning environments with students (Drent \& Meelissen, 2008; ISTE, 2008; UNESCO, 2011). In addition, technology is viewed as a goal of 
Kopish, M. \& Marques, W. Leveraging Technology to Promote Global Citizenship in Teacher Education in the United States and Brazil

learning; thus, teachers are encouraged to develop students' technological literacy and prepare them for working and learning in the 21st century with skills like cooperation, communication, problem solving, and lifelong learning (ISTE, 2008; UNESCO, 2011; Voogt \& Pareja Roblin, 2010). However, the knowledge of how to use technology tools to support learning and develop technological literacy remains underdeveloped for many in-service and pre-service teachers (Agyei \& Voogt, 2011; Crook, 2012; Drent \& Meelissen, 2008; Houston \& Pierson, 2008; Lei, 2009; Ottenbreit-Leftwich, Glazewski, Newby, \& Ertmer, 2010; Sang et al., 2010; Tondeur et al., 2012) and for many teacher educators as well (Gronseth et al., 2010; Tondeur et al., 2012).

Given these limitations, researchers have identified four domains of teacher educators' technological competence that are needed to foster student teachers' ability to teach and learn with technology: 1) technology competencies - the ability to use technology in general (not specific to teaching and learning); 2) competencies for pedagogical and educational use of technology-teacher educators' competencies in using technology for teaching and learning; 3) beliefs about teaching and learning-teacher educators' beliefs about education; and 4) competencies for innovation and professional learning-competencies related to changing pedagogical practices and to professional development (Uerz, Volman, \& Kral, 2018, p. 17).

\section{Teachers' Global Competencies}

Global competence is defined as "the capacity and disposition to understand and act on issues of global significance" (Boix-Mansilla \& Chua, 2016, p. 3). Through educational opportunities and experiences, globally competent students should be able to: 1) investigate the world beyond their immediate environment; 2) recognize perspectives of others and their own; 3) communicate ideas effectively with diverse audiences; and 4) take action to improve conditions (Boix-Mansilla \& Jackson, 2011, p. 11). Student development of global competencies, however, requires educational experiences facilitated by globally competent teachers.

Globally competent teachers possess "a body of knowledge about world regions, cultures, and global issues, and the skills and dispositions to engage responsibly and effectively in a global environment" (Longview Foundation, 2008, p. 7). In practice, globally competent teachers are able to employ a range of pedagogies that guide students through international and crosscultural experiences; engage them in diverse content, multiple perspectives and critical inquiry; and facilitate authentic opportunities for students to take action (Kopish, 2017). The role of teacher educators in the preparation of future globally competent teachers is crucial (Reynolds, Ferguson-Patrick, \& McCormack, 2013; Williams, 2014; Zong et al., 2008). However, in a crowded curriculum driven by standards and accreditation, teacher education programs are oriented in local rather than global contexts (Zhao, 2010). Teacher education programs in the U.S. are among the least internationalized (Knight et al., 2015; Longview Foundation, 2008), and teacher candidates have limited exposure to global content, courses, and experiences during teacher preparation (Kirkwood-Tucker, 2009; Rapoport, 2009, 2010; Steinemann et al., 2001; Zong, 2009). Despite recent efforts to incorporate global competencies in professional standards for teachers (Aydarova \& Marquardt, 2016; Kirby \& Crawford, 2012), the training and 
Kopish, M. \& Marques, W. Leveraging Technology to Promote Global Citizenship in Teacher Education in the United States and Brazil

preparation of teachers has not kept up with the demands or needs of a global society (Apple, 2001; O’Connor \& Zeichner, 2011; Osler \& Vincent, 2002).

The preparation of future teachers is a challenging enterprise. Teacher educators must select among competing priorities to meet all the demands of the profession and develop technological and global competencies. However, the development of teachers who are technologically and globally competent can be viewed as complementary if structured correctly; opportunities for curricular innovation exist. Researchers in teacher education, for example, have used technology to engage teacher candidates in intercultural dialogue with people from around the world (Gaudelli, 2006), virtual intercultural exchanges (Hossain \& Aydin, 2011; Journell \& Dressman, 2011; Malone \& Wilder, 2008), wiki collaborations (Ertmer et al., 2011), and Weblogs (Steven and Brown, 2011), as well as asynchronous discussion threads (Brantmeier, Aragon, \& Folkestad, 2011; Wade et al., 2008) and synchronous discussion threads followed by face-to-face communication (Hoter, Shonfield, \& Ganayi, 2009).

\section{Virtual Technologies and Intercultural Exchange in Education}

In a globalizing world, intercultural interactions and exchanges have become an important educational goal for institutions of higher education. Social networks, mobile devices, and video conferences are among several computer-mediated tools that "constitute a new way of understanding social participation and collaboration" (Guerin, Cigognini, \& Pettenati, 2010, p. 199). Today's students are able to explore the world virtually through innovative curricular models and online environments that offer resources and tools and link students in different parts of the world to promote collaboration (Belz \& Kinginger, 2002; O'Dowd, 2014; Thorne, 2010). These online environments, or virtual spaces, increase opportunities for students to learn from interaction with people of different cultural backgrounds (Raffaghelli \& Richieri, 2012)

The rise of virtual spaces offers new pedagogical and curricular opportunities for educators as well. With origins dating back to the 1990s, virtual spaces that promote international collaboration have been identified by different iterations and incarnations (cf., O'Dowd, 2018) such as virtual exchange (Helm, 2015), telecollaboration (Guth, Helm, \& O'Dowd, 2012; O'Dowd \& Ware, 2009) and Collaborative Online International Learning (COIL) (Rubin \& Guth , 2015). Virtual exchange is the broad term to describe methods of engaging students in online collaborative projects with international partner classes under the guidance of teachers or trained facilitators (O'Dowd \& Lewis, 2016); these exchanges have been implemented in foreign language education, business studies, and initial teacher education (Cummins \& Sayers, 1995; Helm, 2018; O'Dowd, 2018; Warschauer, 1996; Whyte \& Gijsen, 2016). It is important to note, however, that "the idea of introducing telecollaboration as a tool in subject areas outside of foreign language education appears to be quite new" (O'Dowd, 2016, p. 288).

Virtual exchange is based on student-centered, international, and collaborative approaches to learning, which facilitate knowledge construction through interaction and negotiation with 
Kopish, M. \& Marques, W. Leveraging Technology to Promote Global Citizenship in Teacher Education in the United States and Brazil

students from other cultures. It is an educational approach that involves a commitment to experiential learning, collaborative critical inquiry, and cross-curricular learning (Cummins \& Sayers, 1995). Educational goals of virtual exchange include the development of transversal skills, digital literacies, intercultural awareness, and the ability to collaborate effectively with people of different cultural backgrounds (Guth \& Helm, 2010). In teacher education, using technology to create digital spaces for collaborative learning enhances the professional knowledge base for teaching and facilitates pre-service teachers' development of technological competence and engagement with cross-cultural, international peer reflection and dialogic learning (Dooly, 2017; Guichon, 2009; Hubbard \& Levy, 2006; McNeil, 2013; Menter, Hulme, Elliot, \& Lewin, 2010). Among the different types of virtual exchanges, one promising practice is Collaborative Online International Learning (COIL).

\section{Collaborative Online International Learning (COIL)}

Collaborative Online International Learning (COIL) is a type of virtual exchange that promotes cross-cultural development among professors and students without learners and instructors leaving campus ((McKinnon, Smith, \& Thomson, 2015). As an instructional method, COIL virtually links two (or more) institutions together to examine different cultures and national experiences and may also involve interpretations of subject content. In the COIL model, students are enrolled in separate courses at their home institutions and receive grades from their respective professors. The courses may be within the same discipline or different disciplines and collaborative in that faculty have constructed an online module within each course with shared learning objectives, learning tasks, and a culminating project. The collaborative components of COIL courses can vary by durations of time (i.e., four weeks, entire semester), format (i.e., face-to-face, blended or online courses), meeting (i.e., asynchronous, synchronous) depending on academic calendars of the institutions, time differences between countries, and learning objectives of the modules (Rubin \& Guth, 2015).

According to O'Dowd (2018), there are many different approaches to designing and enacting virtual exchange in higher education, such as subject-specific (i.e., foreign language learning and business studies initiatives), a service provider approach (i.e., facilitated through service providers), and a shared syllabus approach (i.e., COIL). The shared syllabus approach to COIL, employed exclusively in this study, includes the addition of international perspectives to course syllabi and structures shared course assignments or tasks to promote the development of digital competence and intercultural competence (O'Dowd, 2018). The sequence of tasks is based on the progressive exchange model (O'Dowd \& Ware, 2009) covering three phases of information exchange, comparing and analyzing cultural practices, and working on a collaborative project. The first type of task, information exchange, involves partners introducing themselves by providing information about biographies, interests, and cultures. The second type of task asks students to make critical comparisons and analyses of cultural products from both cultures (e.g., newspapers, magazines, books, etc.). Finally, the third type of task is collaborative, which requires students to work together to produce a joint product or conclusion together. 
Kopish, M. \& Marques, W. Leveraging Technology to Promote Global Citizenship in Teacher Education in the United States and Brazil

\section{Conceptual Framework}

It is important to acknowledge the pedagogical perspectives that guide the authors' thinking about teacher education in general and in the design of COIL activities specifically. The course activities and experiences were developed from a sociocultural perspective that learning is a socially mediated process (Lave \& Wenger, 1991; Vygotsky, 1978). The online collaborative activities required students to communicate across a variety of modes including text, speech, and multimedia formats, reflecting Vygotsky's (1978) theory of the importance of language in learning. Moreover, students were engaged in situated activities that occurred within social practice contexts (Lave \& Wenger, 1991). Specifically, students engaged in real-world contexts where the nature of the interactions among learners, the tools used within the interactions, the activity itself, and the social context in which the activity takes place shaped learning.

In order for social interactions to lead to development, the interactions were situated in activities that had clear goals and purposes. Guided by the global competence (Boix-Mansilla \& Jackson, 2011) and technological competence frameworks (Uerz, Volman, \& Kral, 2011), all required tasks were hands-on, interactive, and experiential in nature. Experiential learning suggests that students comprehend information when actively participating in experiences related to the concepts they are learning (Scales, Roehlkepartain, Neal, Kielsmeier, \& Benson, 2006) and promotes changes in mental associations and behaviors due to specific experiences (Ormod, 1990). The COIL experiences provided future teachers with rich environments of social interaction (Lave \& Wenger, 1991; Vygotsky, 1986) that promoted technological, cross-cultural, and dialogic learning in an iterative, reflective cycle.

\section{Methods}

\section{Research Design}

For this research, the authors conducted a reflective inquiry (Adler, 1993; Tabachnick \& Zeichner, 1991) to address the following research questions:

To what extent did pre-service teachers' participation in COIL activities help to develop global competencies?

To what extent did pre-service teachers' participation in COIL activities help to develop preservice teachers' ability to employ emerging technologies for learning?

Because the COIL approach was offered for the first time, the authors demonstrated inquiry as stance (Cochran-Smith \& Lytle, 1999, 2009), which "positions practitioners' knowledge, practitioners and their interactions with students and other stakeholders at the center of educational transformation" (2009, p. 123)-in this case, the enactment of COIL activities for the development of pre-service teachers' global competencies and ability to employ technologies for learning. 
Kopish, M. \& Marques, W. Leveraging Technology to Promote Global Citizenship in Teacher Education in the United States and Brazil

\section{Participants}

Study participants included a total of 22 university students enrolled in teacher education programs in the United States $(n=12)$ and Brazil $(n=10)$. Students from the United States were enrolled in a required undergraduate pre-service teaching methods course, while students in Brazil were enrolled in a required graduate course focused on work, education, and professional identity. The course in the United States was offered for three hours on Thursdays from January to May, 2019, and the Brazilian course met for five hours on Fridays from March to June, 2019.

\section{Confidentiality}

IRB approval for this study was obtained for the 12 teacher candidates in the United States. To avoid coercion, written consent was collected from participants on the final day of the methods course by a colleague and not shared with the author until after final grades were due. To preserve anonymity and confidentiality, participant names are not included in this study.

\section{Procedures}

The design and enactment of virtual exchange in this study involved a shared syllabus approach to COIL, which included the addition of international perspectives to both course syllabi and shared course assignments or tasks that promoted the development of digital competence and intercultural competence (O'Dowd, 2018). The curricular project involved four opportunities for pre-service teachers to learn with and from each other, employing different technologies based on the progressive exchange model phases of information exchange, comparing and analyzing cultural practices, and working on a collaborative project (O'Dowd \& Ware, 2009). First, in the information exchange phase, pre-service teachers participated in digital storytelling (Di Blas \& Paolini, 2013), which involved creating videos with mobile devices and video editing software on topics of teacher education, professional identity, and cultural comparisons. Second, during the comparing and analyzing cultural practices phase, pre-service teachers uploaded videos to a private YouTube channel, translated and closed captioned in Portuguese or English, and viewed videos of a partner from the respective institution. Third, as partners viewed videos, they prepared questions for an intercultural interview and cross-cultural dialogue using WhatsApp (a social media and messaging platform) and Google Translate. Finally, for the working on a collaborative project phase, all pre-service teachers participated in a synchronous Skype videoconference facilitated by the two authors on topics of educational reform and teacher identity in the respective countries.

\section{Data}

Data were collected in different forms to enhance the credibility of findings. During each phase of the project, pre-service teachers completed course assignments, wrote reflective journals of their experiences, and participated in whole-group reflective debriefing discussions and 
Kopish, M. \& Marques, W. Leveraging Technology to Promote Global Citizenship in Teacher Education in the United States and Brazil

informal conversations. Concurrently, the authors kept observational and reflective notes during each phase, met on a weekly basis via Skype to discuss curricular choices of instructors and experiences of students, and reviewed recordings of videoconferences and debriefing discussions.

\section{Analysis}

Data were analyzed using procedures for thematic analysis (Braun \& Clarke, 2006). The first step involved data immersion and thorough readings and viewings to create lists of initial ideas about the data. Second, a semantic approach (Patton, 1990) was employed to generate an initial coding scheme related to previous research and conceptual frameworks for global competencies (Boix-Mansilla \& Jackson, 2011) and technological competence for teacher educators (Uerz, Volman, \& Kral, 2018). Third, codes were sorted into possible themes, compared and adjusted based on relevant data, and thematic relationships were considered. Fourth, themes and examples were reviewed within codes and across the entire data set. Fifth, themes and definitions were created using clear descriptive language and illustrative excerpts and organized as findings in this manuscript.

\section{Findings}

\section{Developing Global Competencies}

Research Question One sought to explore the development of global competencies as a consequence of participation in COIL activities. The following three themes were present in the data: 1) A new and affirming cultural experience; 2) Broadening understanding through perspective taking; and 3) Strategic thinking to express ideas and sustain communication.

\section{A new and affirming cultural experience}

During a debriefing session, the pre-service teachers enrolled in the course expressed surprise that the course activities deviated from prior assumptions and previous experiences in teacher education methods courses. For all pre-service teachers, participating in a virtual exchange using a COIL approach offered students a variety of new experiences. For example, one preservice teacher explained, "I have never been in a situation where the language barrier was the main issue preventing communication." Other teacher candidates offered thoughtful and critical reflections about their limited experiences with people from different cultures and acknowledged, "I have never been outside my own cultural area." It was clear that the COIL approach helped to facilitate pre-service teachers through a new and affirming cultural experience. As one pre-service teacher cogently shared, the class activities "shrank the world for me. We have the ability to interact with so many people across the world and learn new ideas and grow with other cultures through technology, and this program helped me learn how to use these tools to do just that." 
Kopish, M. \& Marques, W. Leveraging Technology to Promote Global Citizenship in Teacher Education in the United States and Brazil

What helped pre-service teachers navigate cultural and linguistic differences was their desire and ability to identify similarities with their Brazilian partners, which helped to form positive connections and associations across differences. For example, during a debriefing session, three pre-service teachers offered a similar sentiment: "that it can be helpful and impactful to meet others who are different from you in order to learn more about a new culture and gain new views on certain subjects or topics." It was clear from the discussions and affirmative body language of other participants that digital storytelling, as an entry activity to COIL, helped to form powerful human connections across geographic distance and set a positive foundation for future activities.

\section{Broadening understanding through perspective taking}

Pre-service teachers broadened their understanding through perspective taking. This theme, represented in the data, aligned with a core attribute of the global competency recognize perspectives: that students "recognize and express their own perspective and identify influences on that perspective" (Boix-Mansilla \& Jackson, 2011, pg. 12). To illustrate, students shared the discussions with Brazilian partners, reflecting multiple perspectives, which allowed them to "see different ideas from new perspectives other than my own or even my family's." Digital storytelling, intercultural interviews, and synchronous videoconferences all focused on topics of teacher education, professional identity, and cultural comparisons. These repeated topics, represented in multiple modes, challenged pre-service teachers' assumptions and knowledge. Pre-service teachers repeatedly acknowledged their limited knowledge of history, culture, and issues in Brazil and other countries. However, the structure of the COIL activities enabled pre-service teachers to "build relationships" with partners and discuss "more than typical 'get to know you' questions," for more substantive topics such as "issues regarding our cultures/politics/education, and how we view the world around us."

For other pre-service teachers, the COIL activities provided key opportunities for critical reflection. As one student shared, "I developed better awareness of my positionality in comparison to Brazil and was able to critically think about how my situations differ from that country." This level of reflection was experienced by many of the pre-service teachers as they considered their own paths to post-secondary education along with their partners. Importantly, students mentioned the benefits of cross-cultural experiences as critical context for learning about cultures from new perspectives. In a journal reflection, an aspiring foreign language preservice teacher admitted that they "still had a lot to learn" about culture, but through communication and interactions, they learned that although "different cultural aspects and characteristics of countries can vary greatly from place to place, learning about... subtle differences is when you can really begin to understand a place." Being able to talk about culture and issues related to culture, politics, and education in meaningful ways helped to reshape how pre-service teachers viewed the world. 
Kopish, M. \& Marques, W. Leveraging Technology to Promote Global Citizenship in Teacher Education in the United States and Brazil

\section{Strategic thinking to express ideas and sustain communication}

The COIL activities required students from Brazil and the U.S. to differentiate listening and speaking communication practices, both verbal and nonverbal, and bridge the barrier of not having a shared common language. Moreover, the students had to select and use technology and media to communicate with partners. Taken together, the students engaged in strategic thinking to express ideas and sustain communication. This theme aligns with a second global competency, communicate ideas, and was mentioned by pre-service teachers as they learned to communicate their ideas effectively with diverse audiences. Some key attributes of communicate ideas include: listen to and communicate effectively with diverse people; select and use appropriate technology and media to communicate with diverse audiences; reflect on how effective communication affects understanding and collaboration in an interdependent world (Boix-Mansilla \& Jackson, 2011).

All pre-service teachers were challenged by the disorienting dilemma (Meizrow, 1978, 1990) of communicating across a language barrier, for none spoke Portuguese, nor did their partners speak English. The students, however, were quick to share strategies and tools they employed to ensure the ideas expressed in the activities were communicated clearly with their partners. Some pre-service teachers shared strategies that involved focusing on positive interactions to "build trust" and "seek to find common interests." Others spoke of the importance of augmenting communication with visuals. As one shared during a debriefing after producing digital storytelling videos, "I was deliberate in my choices to include pictures for explanations of things that I knew would probably not translate in the same way. This ensured my partner was still making a connection without needing a direct written translation."

In the third set of COIL activities, students viewed videos, prepared questions, and engaged in a synchronous intercultural interview using WhatsApp and Google Translate. Reflective journals and class debriefing sessions revealed that pre-service teachers leveraged technology and non-technology options to communicate across language barriers. Most pre-service teachers expressed a similar sentiment, as represented by this quote: "Google Translate was helpful. Even though our pronunciation of the words was not always perfect, they still got the general idea of what we were trying to say." With a sense of accomplishment, a few pre-service teachers indicated that Google Translate helped them learn some words in Portuguese. When reliance on Google Translate waned, pre-service teachers employed a strategy of modifying their speech. For example, when students realized their speech was too fast or words were too complex or idiomatic, they repeated and rephrased more clearly, concisely, and slowly. As one pre-service teacher shared, "I found that I normally had to simplify my speech and be mindful in the order of the words I say so that it was more understandable or easier to translate."

Regardless of mode-producing or viewing digital storytelling videos, intercultural interviews, or participation in a videoconference-pre-service teachers were required to simultaneously manage visual, auditory, and textual material as well as pay close attention to communicative choices, which enabled them to participate in conversations to learn with and from others. 
Kopish, M. \& Marques, W. Leveraging Technology to Promote Global Citizenship in Teacher Education in the United States and Brazil

\section{Developing Technological Competencies}

Research Question Two sought to explore the development of technological competencies as a consequence of participation in COIL activities. The following three themes were present in the data: 1) Cautious confidence and limited connections; 2) Recognizing benefits and utility: Changing beliefs using technology; and 3) Expanding possibilities for teaching and learning with technology.

\section{Cautious confidence and limited connections}

With backpacks, often hurried and disheveled, pre-service teachers entered the methods course on Thursday nights. All students possessed technological devices in one or more forms (i.e., phones, computers, and/or tablets) and successfully demonstrated the ability to employ technologies for tasks such as email, social media, word processing, searches, and in the development of presentations. The course activities and assignments required students to use technologies that were unfamiliar to most. For example, weekly assignments required students to use the Google Suite of products (i.e., Drive, Docs, Slides) and various apps. COIL activities required pre-service teachers to use Google Translate to bridge language barriers and facilitate communication in multiple modes. In other cases, students were familiar with tools on their devices and how to use them for social purposes but not for educational purposes. To illustrate, the sentiment of one pre-service teacher was shared by many: "I have recorded a video on my phone, but never edited or created captions; I use Facetime to video chat, but never WhatsApp or Skype as part of a class."

Scaffolding the use of technology through novel tasks, workshops, and assignments was critical, allowing pre-service teachers to become familiar with new technologies. Repeated practice using different technologies helped to build confidence in utilizing technologies in unique ways. Prior to the workshops, students were unfamiliar with resources like Google Translate and WhatsApp. Students learned "how useful these apps are when it comes to communicating with others who do not speak the same language" and expressed confidence in "showing someone else how to use these resources so they can effectively communicate with me." This sentiment, however, also demonstrates a limitation expressed by many. On the one hand, feeling confident in showing someone else how to use a technology is important. The limitation, on the other hand, is that pre-service teachers were unable to meaningfully connect the use of technology with pedagogy or content.

\section{Recognizing benefits and utility: Changing beliefs using technology}

Pre-service teachers recognized the benefits of using technology for teaching and learning and expressed an interest in using it in future classrooms. As one student shared, "These were all valuable experiences that allowed me to deepen my knowledge of different tools that I will be able to and probably will use in the future in my classroom." Among the students who recognized the benefits and utility of using technology, they expressed appreciation and value 
Kopish, M. \& Marques, W. Leveraging Technology to Promote Global Citizenship in Teacher Education in the United States and Brazil

in learning examples of how to use technology for cross-cultural activities. Other pre-service teachers found utility in different technologies for promoting an inclusive classroom. For example, pre-service teachers made direct connections between technologies that help bridge communication barriers, such as using Google Translate with students or families that speak different home languages. As one student shared, "Even with its faults, as it isn't perfect in translation, it encourages discussion between people of different cultures and languages, and I would want that in my future classroom." Collectively, students identified practical technology uses that could be replicated and applied in future educational contexts.

\section{Expanding possibilities for teaching and learning with technology}

"Got me thinking" was the clause used with the greatest frequency by pre-service teachers in written reflections and discussions. To illustrate, a student might begin with an opening sentence such as, "My experience with students in Brazil got me thinking about all the ways that I will have to make the most effective use of the technologies we learned." What followed "got me thinking" were often rich examples of pre-service teachers' reflections on the use of technology and how empowered they felt to expand possibilities for teaching and learning with technology.

For some pre-service teachers, it was the ways in which they used different technology tools and mediums to create new projects. The digital storytelling projects were mentioned as the most enjoyable activity because the design and production phases of the project required focus and unleashed pride and creativity. As one pre-service teacher offered, "I worked hard to become acquainted with [various technologies] in order to make a visually appealing and clear video for my partner to understand. These projects pushed me to expand my horizons on using different forms of media to create informative and fun projects." It was clear that students understood the importance of effective communication across language barriers and sought to create quality videos for their Brazilian partners.

Engaging in the COIL activities and in-class workshops exposed pre-service teachers to new apps and technology tools. As familiarity with and confidence in using different technologies increased, students also shared that when they encountered problems, new solutions were found. In other words, repeated exposure and practice helped to expand a repertoire of tools to complete the different tasks. When students struggled with one tool, they described instances of "finding another way to use technology." Rather than shutting down, the students shared examples of how they persisted by switching between tools and products; for example: WhatsApp to Skype, Google Translate to iTranslate or translation in Skype, iMovie to HitFilm, and device recording to Screencastify. Developing competencies across multiple platforms, devices, and tools encouraged pre-service teachers to consider ways to improve the COIL activities for the class and in future ways to promote student learning. For example, with great excitement, one student shared, "I thought of so many things that we could do to learn more about the Brazilians, communicate about teaching, even collaborate on creating lesson plans. These experiences enhanced my creativity and thinking about how I am going to use limited 
Kopish, M. \& Marques, W. Leveraging Technology to Promote Global Citizenship in Teacher Education in the United States and Brazil

resources in order to maximize student learning to the fullest potential." All pre-service teachers believed their abilities and skills using and selecting technology improved throughout the semester. Importantly, the pre-service teachers also expressed that they could still use more work and practice with technology in order to be effective practitioners in future classrooms. The COIL experiences sparked an interest in looking for professional learning and professional development opportunities to improve their ability to use technologies as users and educators.

\section{Discussion}

Toward the goal of developing global competencies among pre-service teachers through COIL activities, the findings reported in this study are promising. The results, however, are limited to the experiences of teacher candidates $(n=12)$ at one university in the United States; those enrolled in the course represent a small sample. While the small sample size was comparable to other qualitative studies (Harshman, 2016b; Maguth, 2014; Parkhouse, Tichnor-Wagner, Cain, \& Glazier, 2016), a larger sample of pre-service teachers would likely reveal critical differences in perspectives in the development of global and technological competencies. Moreover, the inclusion of data from international partners would be a welcome addition to this study and will require the authors to mitigate differences in institutional IRB procedures for international research.

\section{Global Competencies}

Despite these limitations, the quality and structure of the COIL activities contributed to the development of global competencies with pre-service teachers at a state university in the Midwestern United States. Specifically, the findings indicate that pre-service teachers considered the COIL activities a new and affirming cultural experience that helped to broaden their understanding through perspective taking and encouraging strategic thinking to express ideas and sustain communication across linguistic barriers. These findings align with two domains of global competence outlined by Boix-Mansilla and Jackson (2011): recognize perspectives and communicate ideas. The development of intercultural and communicative global competencies is largely due to the emphasis of the COIL tasks, which involved information exchange through digital storytelling, making comparisons and analyses of cultural products through the review of digital storytelling videos and intercultural interviews, and a collaborative videoconference to explore issues of teacher identity and education policy. In the shared syllabus COIL approach, assignments and tasks are designed to develop intercultural competence (O'Dowd, 2018).

Notably absent in these data was evidence related to the global competence of investigating the world and taking action (Boix-Mansilla \& Jackson, 2011), which exposed a limitation in the design of the COIL tasks and offers guidance for future collaborative COIL activities. In the progressive exchange model offered by O'Dowd and Ware (2009), working on a joint project is a third type of task in the COIL approach. There are endless possibilities for engaging students 
Kopish, M. \& Marques, W. Leveraging Technology to Promote Global Citizenship in Teacher Education in the United States and Brazil

in collaborative tasks to produce a joint product. For example, future activities could involve a collaborative inquiry project to explore an educational policy issue from multiple perspectives. A COIL activity could involve students evaluating evidence, developing arguments and defensible conclusions, and designing opportunities to take action personally or collaboratively. Or, perhaps students could participate in a COIL activity that involved a cycle of co-designing a lesson plan, teaching the lesson plan, engaging in critical reflection, and re-designing the lesson plan. Each of these examples encourages students to engage in practices and tasks that could be viewed as a more integrative approach to developing global competencies across four domains: investigate the world beyond their immediate environment; recognize perspectives; communicate ideas; take action (Boix-Mansilla \& Jackson, 2011). Future projects should also be designed to create unique experiences for students to engage in critical pedagogy and attend to issues of power and privilege that reproduce inequality (Friere, 1970). This would help move the COIL tasks in this study beyond reflective and comparative activities related to identity and issues in education to activities that engage students in praxis as critical educators and citizens.

\section{Technological Competencies}

In the shared syllabus COIL approach, assignments and tasks are also designed to develop digital competence (O'Dowd, 2018). The second research question in this study focused on the extent to which COIL activities helped develop technological competencies or the ability to employ emerging technologies for learning. While there are main iterations of technological competencies (Hamel, 2007; ISTE 2017; Moore \& Simon, 2015; Partnership for 21st Century Skills, 2011; Stearns, 2009; West, 2010), the domains of competence that informed this study include: general abilities, pedagogical and educational use, beliefs about teaching and learning, and innovation and professional learning (Uerz, Volman, \& Kral, 2018). The findings reported in this study indicate that pre-service teachers have cautious confidence and limited connections with technologies. Participating in COIL activities, however, expanded pre-service teachers' repertoire of experiences using different technologies, which helped them recognize the benefits and utility and ultimately changed their beliefs about using technology. By the end of the course, pre-service teachers moved from using technology to complete assignments to considering new possibilities for teaching and learning with technology.

Research in teacher education demonstrates that technology is a powerful tool for engaging pre-service teachers globally in intercultural interactions and exchange (Brantmeier, Aragon, \& Folkestad, 2011; Ertmer et al., 2011; Gaudelli, 2006; Hossain \& Aydin, 2011; Hoter, Shonfield, \& Ganayi, 2009; Journell \& Dressman, 2011; Malone \& Wilder, 2008; Wade et al., 2008). Adding to this body of research, findings from this study indicates COIL as a type of virtual exchange and offers great potential for teacher educators to develop global and technological competencies. As pre-service teachers entered the course and started COIL activities, many possessed general technological competencies, which enabled the instructor to showcase new technologies and build upon existing skills. A community of practice emerged for pre-service 
Kopish, M. \& Marques, W. Leveraging Technology to Promote Global Citizenship in Teacher Education in the United States and Brazil

teachers through the structure of the COIL activities, the scaffolding of new technologies, and ongoing support from classmates and the instructor.

The findings in this study offer reasons to be encouraged, but with some caveats. Pre-service teachers engaged with technologies, both familiar and new, in order to complete graded assignments for the course; they leveraged technology for design and communication. While some clearly saw the value of technology for teaching about culture and communicating across language barriers, it remains to be seen whether the pre-service teachers will transfer learning to new contexts and meaningfully connect the use of technology with pedagogy and content (Koehler, Mishra, \& Cain, 2013). Based on some of the student reflections about future plans to use technology in the classroom, pre-service teachers seem most comfortable replicating practices learned or limiting the use of technologies for communicative purposes. It may be of benefit for the authors to consider additional ways to evaluate pre-service teachers' development of technological competencies, perhaps with tasks to design curriculum with technology for the classroom. As this project expands to involve students in collaborative tasks that produce a joint product, the instructors and their students will benefit from inter- or multidisciplinary collaborations outside teacher education to share, discuss, and reflect on lessons with colleagues and technology experts. Collaboration with colleagues and technology experts is a form of professional development that would help expand the instructors' repertoires of practice using technology and help expand opportunities for future COIL activities. Engaging students in the collaborations would be an excellent way to model professional development and further develop skills like cooperation, communication, problem solving, and lifelong learning (ISTE, 2008; UNESCO, 2011; Voogt \& Pareja Roblin, 2010).

\section{Closing}

The world is changing rapidly and its people are increasingly interconnected. A teacher education that includes the development of global and technological competencies is an imperative for the 21st century. Contexts and access to resources and opportunities differ among institutions of higher education and teacher education programs. While there is no prescriptive path, transforming teacher education using a COIL approach is a rewarding endeavor for instructors and has the potential to be a transformative experience for the preservice teachers. 
Kopish, M. \& Marques, W. Leveraging Technology to Promote Global Citizenship in Teacher Education in the United States and Brazil

\section{References}

Adler, S. A. (1993). Teacher education: Research as reflective practice. Teaching and Teacher Education, 9(2), 159-167.

Agyei, D. D., \& Voogt, J. (2011). Exploring the potential of the will, skill, tool model in Ghana: Predicting prospective and practicing teachers' use of technology. Computers \& Education, 56(1), 91-100. https://doi.org/10.1016/ j.compedu.2010.08.017

Apple, M. W. (2011). Global crises, social justice, and teacher education. Journal of Teacher Education, 62(2), 222-234.

Asia Society. (2008). Going global: Preparing our students for an interconnected world. New York: Author.

Aydarova, E., \& Marquardt, S. K. (2016). The global imperative for teacher education: Opportunities for comparative and international education. FIRE: Forum for International Research in Education, 3(1), 23-41.

Belz, J. A., \& Kinginger, C. (2002). The cross-linguistic development of address form use in telecollaborative language learning: Two case studies. Canadian Modern Language Review, 59(2), 189-214.

Blake, R. (2013). Brave new digital classroom: Technology and foreign language learning (2nd ed.). Washington, DC: Georgetown University Press.

Boix-Mansilla, V., \& Jackson, A. (2011). Educating for global competency. Preparing our youth to engage the world. New York: Asia Society.

Branche, J., Mullennix, J., \& Cohn, E. R. (Eds). (2007). Diversity across the curriculum: A guide for faculty in higher education. Bolton: Anker.

Braun, V., \& Clarke, V. (2006). Using thematic analysis in psychology. Qualitative Research in Psychology, 3(2), 77-101.

Brewer, E., \& K. Cunningham (Eds.). (2009). Integrating study abroad into the curriculum. Sterling, VA: Stylus.

Cator, K. (2010). How do you define 21st-century learning? Education Week Teacher Professional Development Sourcebook: Editorial Projects in Education, 11 Oct. 2010. Retrieved from http://www.edweek.org/tsb/articles/ 2010/10/12/01panel.h04.html 
Kopish, M. \& Marques, W. Leveraging Technology to Promote Global Citizenship in Teacher Education in the United States and Brazil

Ceo-DiFrancesco, D. (2015). Engaging learners in culturally authentic virtual interactions. In A. Moeller (Ed.), Learn languages, explore cultures, transform lives: Central states conference report (pp. 39-57). http://www.csctfl.org/documents/2015Report/CSCTFL\%20Report 2015.pdf

Chun, D. M. (2011). Developing intercultural communicative competence through online exchanges. CALICO Journal, 28(2), 392-419.

Cochran-Smith, M., \& Lytle, S. (1999). Relationships of knowledge and practice: Teacher learning in communities. In A. Iran-Nejad \& C. Pearson (Eds.), Review of research in education (Vol. 24, pp. 249-306). Washington, DC: American Educational Research Association.

Cochran-Smith, M., \& Lytle, S. (2009). Inquiry as stance: Practitioner research for the next generation. New York: Teachers College Press.

Cooper, J. L., Robinson, P., \& McKinney, M. (1993). Cooperative learning in the classroom. In D. F. Halpern \& Associates, Changing college classrooms (pp. 74-92). San Francisco: Jossey-Bass.

Cummins, J., \& Sayers, D. (1995). Brave new schools: Challenging cultural illiteracy through global learning networks. New York: St. Martin's Press.

Davis, A. (2004). Co-authoring identity: Digital storytelling in an urban middle school. THEN: Technology, Humanities, Education, \& Narrative, 1(1), 1-21.

Dooly, M. (2017). Telecollaboration. In C. A. Chapelle \& S. Sauro (Eds.), The handbook of technology in second language teaching and learning (pp. 169-183). Hoboken, NJ: Wiley-Blackwell.

Dooly, M., \& O'Dowd, R. (Eds.). (2012). Researching online foreign language interaction and exchange: Theories, methods and challenges. Bern: Peter Lang. Retrieved from https://doi.org/10.3726/978-3-0351-0414-1/4

Drent, M., \& Meelissen, M. (2008). Which factors obstruct or stimulate teacher educators to use ICT innovatively? Computers \& Education, 51(1), 187-199. https://doi.org/10.1016/j.compedu.2007.05.001

Freire, P. (1973). Education for critical consciousness. New York, NY: Seabury Press.

Gaudelli, W. (2006). Convergence of technology and diversity: Experiences of two beginning teachers in web-based distance learning for global/multicultural education. Teacher Education Quarterly, 26(1), 97-106. 
Kopish, M. \& Marques, W. Leveraging Technology to Promote Global Citizenship in Teacher Education in the United States and Brazil

Gronseth, S., Brush, T., Ottenbreit-Leftwich, A., Strycker, J., Abaci, S., Easterling, W., et al. (2010). Equipping the next generation of teachers: Technology preparation and practice. Journal of Digital Learning in Teacher Education, 27(1), 30-36. https://doi.org/10.1080/21532974.2010.10784654.

Guerin, E. M. C., Cigognini, M. E., \& Pettenati, M. C. (2010). Learner 2.0. In S. Guth \& F. Helm (Eds.), Telecollaboration 2.0: Language, literacies and intercultural learning in the 21st century (pp. 199-218). Bern, Switzerland: Peter Lang.

Guichon, N. (2009). Training future language teachers to develop online tutors' competence through reflective analysis. ReCALL, 21(2), 166-185. https://doi.org/10.1017/S0958344009000214

Gurung, R. A. (2009). Got culture? In R. A. Gurung \& L. R. Prieto (Eds.), Getting culture (pp. 11-22). Sterling, VA: Stylus.

Guth, S., \& Helm, F. (Eds). (2010). Telecollaboration 2.0: Language, literacies and intercultural learning in the 21st century. Bern, Switzerland: Peter Lang.

Guth, S., Helm, F., \& O’Dowd, R. (2012). University language classes collaborating online - Report on the integration of telecollaborative networks in European universities. Retrieved from http://www.unicollaboration.org/wpcontent/uploads/2016/06/1.1-Telecollaboration report Executive summaryOct2012 0.pdf

Hamel, G. (2007). The future of management. Cambridge, MA: Harvard Business School Press.

Helm, F. (2018). The long and winding road... Journal of Virtual Exchange. Retrieved from: https://doi.org/10.14705/rpnet.2018.jve.3

Houston, W. R., \& Pierson, M. E. (2008). Preparing teachers for a global society that is yet unknown to teacher educators. Teacher Education and Practice, 21(4), 479-481.

Hoter, E., Shonfield, M., \& Ganayi, A. (2009). Information and communication technology (ICT) in the service of multiculturalism. International Review of Research in Open and Distance Learning, 10(2), 1-15.

Hubbard, P., \& Levy, M. (Eds.). (2006). Teacher education in CALL. Amsterdam: John Benjamins. 
Kopish, M. \& Marques, W. Leveraging Technology to Promote Global Citizenship in Teacher Education in the United States and Brazil

International Society for Technology in Education (ISTE). (2008). ISTE standards for teachers. Retrieved from http://www.iste.org/standards/iste-standards/ standards-for-teachers

Journell, W., \& Dressman, M. (2011). Using videoconferences to diversify classrooms electronically. Clearing House: A Journal of Educational Strategies, Issues and Ideas, 84(3), 109-113.

Kim, B. S., \& Lyons, H. Z. (2003). Experiential activities and multicultural counseling competence training. Journal of Counseling and Development, 81, 400-408.

Kirby, M. M., \& Crawford, E. O. (2012). The preparation of globally competent teachers: A comparison of American and Australian education policies and perspectives. Global Partners in Education Journal, 2(1), 12-24.

Kirkwood-Tucker, T. F. (Ed.). (2009). Visions in global education: The globalization of curriculum and pedagogy in teacher education and schools: Perspectives from Canada, Russia, and the United States (Vol. 29). New York: Peter Lang.

Knight, S., Lloyd, G., Arbaugh, F., Gamson, D., McDonald, S., Nolan Jr., J., \& Whitney, A. (2015). Contextualizing versus internationalizing research on teacher education: Competing or complementary goals? Journal of Teacher Education, 66(3), 197200.

Koehler, M. J., Mishra, P., \& Cain, W. (2013). What is technological pedagogical content knowledge (TPACK)? Journal of Education, 193(3), 13-19.

Kopish, M. A. (2016). Preparing globally competent teacher candidates through cross cultural experiential learning. Journal of Social Studies Education Research, 7(2), 75-108.

Kopish, M. A. (2017). Global citizenship education and the development of globally competent teacher candidates. Journal of International Social Studies, 7(2), 20-59.

Kumaravadivelu, B. (2006) Understanding language teaching: From method to postmethod. Mahwah, NJ: Lawrence Erlbaum Associates.

Lambert, J. (2007). Digital storytelling cookbook. San Francisco: Digital Diner Press.

Lave, J., \& Wenger, E. (1991). Situated learning: Legitimate peripheral participation. Cambridge, MA: Cambridge University Press. 
Kopish, M. \& Marques, W. Leveraging Technology to Promote Global Citizenship in Teacher Education in the United States and Brazil

Lewis, T., \& O'Dowd, R. (2016). Introduction to online intercultural exchange and this volume. In R. O'Dowd \& T. Lewis (Eds.), Online intercultural exchange: Policy, pedagogy, practice (pp. 3-20). New York: Routledge.

Lindsay, J., \& Redmond, P. (2017). Online global collaboration: Affordances and inhibitors. In Me, Us, IT! Proceedings ASCILITE2017: 34th International Conference on Innovation, Practice and Research in the Use of Educational Technologies in Tertiary Education (pp. 293-303). University of Southern Queensland.

Longview Foundation. (2008). Teacher preparation for the global age: The imperative for change. Silver Spring, MD: Longview Foundation.

McKinnon, S., Smith, A. \& Thomson, J. (2015). A window to the world: Technology to internationalize entrepreneurship education. Journal of Perspectives in Applied Academic Practice, 3(3), 15-23.

McNeil, L. (2013). Exploring the relationship between situated activity and CALL learning in teacher education. ReCALL, 25(2), 215-232. https://doi.org/10.1017/ S0958344013000086

Menter, I., Hulme, M., Elliot, D., \& Lewin, J. (2010). Literature review on teacher education in the 21st century. Edinburgh: Education Analytical Services.

Moore, A. S., \& Simon, S. (2015). Globalization in the humanities and the role of collaborative online international teaching and learning. In A. S. Moore \& S. Simon (Eds.), Globally networked teaching in the humanities: Theories and practices (pp. 1-9). New York: Routledge.

National Association of Foreign Student Advisors (NAFSA): Association of International Educators. (2018). Trends in U.S. study abroad. Retrieved from https://www.nafsa.org/Policy and Advocacy/Policy Resources/Policy Trends a nd Data/Trends in U S Study Abroad/

Nilson, L. B. (2010). Teaching at its best. San Francisco: Jossey-Bass.

O'Connor, K., \& Zeichner, K. (2011). Preparing US teachers for critical global education. Globalisation, Societies and Education, 9(3-4), 521-536.

O'Dowd, R. (2007). Evaluating the outcomes of online intercultural exchange. ELT Journal, 61(2), 144-152. 
Kopish, M. \& Marques, W. Leveraging Technology to Promote Global Citizenship in Teacher Education in the United States and Brazil

O'Dowd, R. (2010). Issues in the assessment of online interaction and exchange. In S. Guth \& F. Helm (Eds.), Telecollaboration 2.0: Language, literacies and intercultural learning in the 21st century (pp. 337-360). Bern, Switzerland: Peter Lang.

O'Dowd, R. (2011). Online foreign language interaction: Moving from the periphery to the core of foreign language education? Language Teaching, 44(3), 368-380.

O'Dowd, R. (2013). Telecollaborative networks in university higher education: Overcoming barriers to integration. The Internet and Higher Education, 18, 47-53.

O'Dowd, R. (2014). Intercultural communicative competence through telecollaboration. In J. Jackson (Ed.), The Routledge handbook of language and intercultural communication (pp. 340-56). Ubingdon, UK: Routledge.

O'Dowd, R. (2016). Learning from the past and looking to the future of online intercultural exchange. In R. O'Dowd \& T. Lewis (Eds.), Online intercultural exchange: Policy, pedagogy (pp. 273-293). New York: Taylor \& Francis.

O'Dowd, R. (2018). From telecollaboration to virtual exchange: State-of-the-art and the role of UNICollaboration in moving forward. Journal of Virtual Exchange, 1, 1-23. https://doi.org/10.14705/rpnet.2018.jve.1

O'Dowd, R., \& Ritter, M. (2006). Understanding and working with "failed communication" in telecollaborative exchanges. CALICO Journal, 23(3), 623-642.

O'Dowd, R., \& Waire, P. (2009). Critical issues in telecollaborative task design. Computer Assisted Language Learning, 22(2), 173-88.

Ohler, J. (2006). The world of digital storytelling. Educational Leadership, 63(4), 44-47.

Ormrod, J. (1990). Human learning: Principles, theories, and educational applications. Columbus, $\mathrm{OH}$ : Merrill Publishing Co.

Osler, A., \& Vincent, K. (2002). Citizenship and the challenge of global education. London, UK: Trentham.

Ottenbreit-Leftwich, A. T., Glazewski, K. D., Newby, T. J., \& Ertmer, P. A. (2010). Teacher value beliefs associated with using technology: Addressing professional and student needs. Computers \& Education, 55(3), 1321-1335. https://doi.org/10.1016/j.compedu.2010.06.002. 
Kopish, M. \& Marques, W. Leveraging Technology to Promote Global Citizenship in Teacher Education in the United States and Brazil

Paolini, S., Harwood, J., Hewstone, M., \& Neumann, D. L. (2018). Seeking and avoiding intergroup contact: Future frontiers of research on building social integration. Social and Personality Psychology Compass. 12, 1-19.

Partnership for 21st Century Skills. (2011). Framework for 21st century learning. Author. Retrieved from: http://www.p21.org/storage/documents/1. p21 framework 2pager.pdf

Patton, M. Q. (1990). Qualitative evaluation and research methods (2nd ed.). Newbury Park, CA: Sage.

Raffaghelli, J. E., \& Richieri, C. (2012). A classroom with a view: Networked learning strategies to promote intercultural education. In Dirckinck-Holmfield, L., Hodgson, V., and McConnell, D. (Eds.) Exploring the theory, pedagogy and practice of networked learning (pp. 99-119). New York: Springer.

Rapoport, A. (2009). A forgotten concept: Global citizenship education and state social studies standards. The Journal of Social Studies Research, 33(1), 91-112.

Rapoport, A. (2010). We cannot teach what we do not know: Indiana teachers talk about global citizenship education. Education, Citizenship, and Social Justice, 5(3), 179190.

Reynolds, R., Ferguson-Patrick, K., \& McCormack, A. (2013). Dancing in the ditches: Reflecting on the capacity of a university/school partnership to clarify the role of a teacher educator. European Journal of Teacher Education, 36(3), 307-319.

Rubin, J., \& Guth, S. (2015). Collaborative online international learning: An emerging format for internationalizing curricula. In A. S. Moore \& S. Simon (Eds.), Globally networked teaching in the humanities: Theories and practices (pp. 15-27). New York: Routledge.

Sadik, A. (2008). Digital storytelling: A meaningful technology-integrated approach for engaged student learning. Educational Technology Research \& Development, $56(4), 487-506$

Sang, G., Valcke, M., Van Braak, J., \& Tondeur, J. (2010). Student teachers' thinking processes and ICT integration: Predictors of prospective teaching behaviours with educational technology. Computers \& Education, 54(1), 103-112. https://doi.org/10.1016/j.compedu.2009.07.010. 
Kopish, M. \& Marques, W. Leveraging Technology to Promote Global Citizenship in Teacher Education in the United States and Brazil

Scales, P. C., Roehlkepartain, E. C., Neal, M., Kielsmeier, J. C., \& Benson, P. L. (2006). Reducing academic achievement gaps: The role of community service and service learning. Journal of Experiential Education, (29), 38-60.

Schenker, T. (2013). The effects of a virtual exchange on students' interest in learning about culture. Foreign Language Annals, 46(3), 491-507.

Stage, F. K., Muller, P.A., Kinzie, J., \& Simmons, A. (1998). Creating learner centered classrooms: What does learning theory have to say? ASHE-ERIC Higher Education Report No.4. Washington, DC: ERIC Clearinghouse on Higher Education and the Association for the Study of Higher Education.

Standish, A. (2012). The false promise of global learning: Why education needs boundaries. New York, NY: Continuum.

Standish, A. (2014). What is global education and where is it taking us? Curriculum Journal, 25(2), 166-186.

Starke-Meyerring, D., \& Wilson, M. (Eds). (2008). Designing globally networked learning environments: Visionary partnerships, policies, and pedagogies. Sense Publishers.

Stearns, P. (2009). Educating global citizens. New York: Routledge.

Steinemann, N. K., Fiske, E. B., \& Sackett, V. (2001). Asia in the schools: Preparing young Americans for today's interconnected world. A report of the national commission on Asia in the schools. New York: Asia Society.

SUNY COIL. (2015). About Coil. Retrieved from http://COIL.Suny.edu

Tabachnick, B., \& Zeichner, K. (1991). Issues and practices in inquiry oriented teacher education. London: Falmer Press.

Thorne, S. L. (2003). Artifacts and cultures-of-use in intercultural communication. Language Learning \& Technology, 7(2), 38-67.

Thorne, S. L. (2010). The intercultural turn and language learning in the crucible of new media. In S. Guth \& F. Helm (Eds.), Telecollaboration 2.0: Language, literacies and intercultural learning in the 21st century (pp. 139-65). Bern, Switzerland: Peter Lang.

Tichnor-Wagner, A., Parkhouse, H., Glazier, J., \& Cain, J. M. (2019). Becoming a globally competent teacher. Alexandria, VA: ASCD. 
Kopish, M. \& Marques, W. Leveraging Technology to Promote Global Citizenship in Teacher Education in the United States and Brazil

Tondeur, J., Van Braak, J., Guoyuan, S., Voogt, J., Fisser, P., \& Ottenbreit-Leftwich, A. S. (2012). Preparing student teachers to integrate ICT in classroom practice: $A$ synthesis of qualitative evidence. Computers \& Education, 59(1), 134-144.

Uerz, D., Volman, M., \& Kral, M. (2018). Teacher educators' competences in fostering student teachers' proficiency in teaching and learning with technology: An overview of relevant research literature. Teaching and Teacher Education, 70, 1223.

UNESCO. (2015). Global citizenship education: Topics and learning objectives. Paris, France.

United Nations Educational, Scientific and Cultural Organization (UNESCO). (2011). UNESCO ICT Competency framework for teachers. Retrieved from http://unesdoc. unesco.org/images/0021/002134/213475E.pdf

Vygotsky, L. S. (1978). Mind in society: The development of higher psychological processes. Cambridge: Harvard University Press.

Wade, S. E., Fauske, J. R., \& Thompson, A. (2008). Prospective teachers' problem solving in online peer-led dialogues. American Educational Research Journal, 45(2), 398442.

Warschauer, M. (1996). Motivational aspects of using computers for writing and communication. In M. Warschauer, (Ed.). Telecollaboration in foreign language learning: Proceedings of the Hawai'I symposium (Technical Report \#12). Honolulu, Hawai'i: University of Hawai'i. Second Language Teaching and Curriculum Center, 29-46.

Whyte, S., \& Gijsen, L. (2016). Telecollaboration in secondary EFL: A blended teacher education course. In S. Jager, M. Kurek, and B. O'Rourke (Eds.), New directions in telecollaborative research and practice: Selected papers from the second conference on telecollaboration in higher education (pp. 163-170). https://doi.org/10.14705/rpnet.2016.telecollab2016.

Wilkinson, J. (2012). The intercultural speaker and the acquisition of intercultural/global competence. In J. Jackson (Ed.), The Routledge handbook of language and intercultural communication (pp. 296-309). Ubingdon, UK: Routledge.

World Savvy. (2015). World savvy. Retrieved from http://www.worldsavvy.org

Zhao, Y. (2010). Preparing globally competent teachers: A new imperative for teacher education. Journal of Teacher Education, 61, 422-431. 
Zong, G., Wilson, A. H., \& Quashiga, A. Y. (2008). Global education. In L. S. Levstik \& C. A. Tyson (Eds.), Handbook of research in social studies education (pp. 197-216). New York: Routledge. 